\title{
Breast cancer imaging features as a predictor of the hormonal receptor status, HER2neu expression and molecular subtype
}

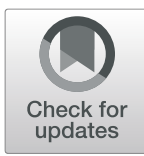

\author{
Maged Abdelfattah Ali Algazzar ${ }^{1 *}$, Elsayed El-Mekkawy Elsayed ${ }^{1}$, Alshimaa Mahmoud Alhanafy²
} and Waleed Abdelfattah Mousa'

\begin{abstract}
Background: Determination of the hormonal receptor (HR) status, HER2neu expression, and the molecular subtype has valuable diagnostic, therapeutic, and prognostic implications for breast cancer as breast cancer stratification during the last two decades has become dependent upon the underlying biology. The aim of this study is to assess the correlation between imaging features of breast cancer and the HR status, HER2neu expression, and the molecular subtype. Sixty breast cancer patients underwent breast ultrasound, mammography, and MRI evaluation. Pathological evaluation using immunohistochemistry and FISH was used to detect the HR status, HER2/neu expression, and the molecular subtype. Those findings were then correlated with the radiologic data.
\end{abstract}

Results: HR-positive tumors were associated with posterior acoustic shadowing (34/44, 77.3\%; $p=0.004$ ). Hormonal-negative tumors presenting as masses were more likely circumscribed on US and MRI compared to hormonal positive mass tumors $(6 / 14,42.9 \%$ vs $3 / 36,7.7 \% ; p=0.003$ on US and 6/13,46.3\% vs 3/36, 8.3\%; $P$ $=0.007$ on MRI) and had malignant DCE kinetics with washout curves compared to the hormonal positive group $(10 / 16,62.5 \%$ vs 4/44, 9.1\%; $P<0.001)$. HER2neu-positive tumors were significantly associated with calcifications and multifocality on mammography compared to HER2neu-negative group (9/13, 69\% vs 12/34, 25.5\%; $P=0.007)$ and $(7 / 13,53 \%$ vs 3/47, 6\%; $P<0.001)$. TNBC and HER2neu-enriched were associated with washout kinetic curve pattern (57.1\% and 66.7\%, respectively). TNBCs were associated with circumscribed margins on US and MRI $(6 / 9,66.7 \% ; P<0.001)$.

Conclusion: Microcalcifications, margins, posterior acoustic features, and malignant washout kinetics strongly correlate with the hormonal receptor status, HER2neu status, and molecular subtype of breast cancer. These findings may suggest the molecular subtype of breast cancer and further expand the role of imaging.

Keywords: Imaging features, Hormonal receptor, HER2neu expression, Molecular subtype, Mammography, Ultrasonography, MRI

\footnotetext{
* Correspondence: maged.algazzar@med.menofia.edu.eg

${ }^{1}$ Department of Radiodiagnosis, Faculty of Medicine, Menoufia University,

Shibin El Kom, Menoufia 32511, Egypt

Full list of author information is available at the end of the article
}

\section{Springer Open}

(c) The Author(s). 2020 Open Access This article is licensed under a Creative Commons Attribution 4.0 International License, which permits use, sharing, adaptation, distribution and reproduction in any medium or format, as long as you give appropriate credit to the original author(s) and the source, provide a link to the Creative Commons licence, and indicate if changes were made. The images or other third party material in this article are included in the article's Creative Commons licence, unless indicated otherwise in a credit line to the material. If material is not included in the article's Creative Commons licence and your intended use is not permitted by statutory regulation or exceeds the permitted use, you will need to obtain permission directly from the copyright holder. To view a copy of this licence, visit http://creativecommons.org/licenses/by/4.0/. 


\section{Background}

Breast cancer constitutes a diverse group of diseases, which can be appreciated by its variable imaging features, histologic and molecular classifications, and its correspondingly variable disease course [1]. The traditional classification of breast cancer depends on the clinicopathologic analysis of tumors, defining breast cancer by histopathologic features. The tumor size, lymph node involvement, local invasion, and distant metastases were then used to decide the treatment choices [2].

However, the traditional classifications do not fully demonstrate the diversity of breast cancer. During the last two decades, breast cancer classifications have been reshuffled, from the histopathologic type to the molecular subtype [3]. Each molecular subtype presents different incidence, response to treatment, recurrence, prognosis, preferred metastatic organs, and disease-free survival outcomes [4]. A detailed molecular classification is a requirement for appropriate treatment and management as the latest generations of anticancer agents are based on biological mechanisms. Since 2011, the recommendations for breast cancer systemic therapies depend on the molecular subtype as per the St. Gallen International Expert Consensus Panel [5].

Clinical biomarkers play important roles in diagnosis and prediction of prognosis and may also represent therapeutic targets. Key breast cancer biomarkers include ER, PR, and HER2/neu. The expression of those markers correlates with differences in tumor behavior and patient outcome and the potential response to targeted endocrine therapy or HER2 therapy. The protein expression levels of ER, PR, and HER2 are assessed using immunohistochemistry and, in addition, the ERBB2 gene copy number is also quantified using in situ hybridization [6].

Patients with hormone receptor-positive $(\mathrm{HR}+)$ breast cancers will likely receive endocrine therapy, while patients with HER2+ breast cancers will receive trastuzumab or other HER2-targeted therapies [7].

As the name suggests, triple-negative breast cancer (TNBC) encompasses all tumors that are negative for ER, PR, and HER2. The majority of TNBC are high grade and aggressive tumors associated with a poorer outcome than other breast cancer subtypes, despite a good response to chemotherapy [8].

Using extensive profiling at the DNA, microRNA, and protein levels, the Cancer Genome Atlas (TCGA) Network classified breast cancer into four molecular subtypes: "luminal A," "luminal B," "HER2-enriched," and "basal-like" [9]. This classification mainly corresponds to hormone receptor and HER2 status and tumoral proliferation [10]. Estrogen receptor (ER), progesterone receptor (PR), and human epidermal growth factor receptor 2 (HER2) expression status are usually determined by immunohistochemistry (IHC) or fluorescence in situ hybridization (FISH). This has important therapeutic and prognostic implications [11].

\section{Methods}

Sixty breast cancer female patients referred to either the diagnostic radiology department or the clinical oncology and nuclear medicine department from January 2017 to December 2018 were evaluated using mammography, ultrasonography, and breast MRI. Tissue sampling was performed via either image-guided biopsy or surgical excision followed by histopathological examination, IHC for ER, PR, HER2, Ki-67 status assessment and FISH for HER2 equivocal cases.

- Inclusion criteria are as follows:

o female gender, age more than 18 years old, and pathological diagnosis of invasive breast carcinoma.

- Exclusion criteria are as follows:

$\circ$ patients whom underwent neoadjuvant chemotherapy or with recurrent breast cancer, patients with lesions only identified on MRI examination, contraindication to perform MRI, and inadequate tissue sample for IHC examination were excluded from this study.

- Imaging acquisition and analysis are as follows:

I. Mammography

- $\quad$ CC and MLO views were performed using Siemens Mammomat Select.

II. Breast ultrasound

- Handheld bilateral complete ultrasound examination via one of the participating radiologists using a (Philips HD 11) ultrasound system with straight linear array probe $(7-12 \mathrm{MHz}$ frequency).

III. DCE-MRI of the breast

* Using a high field strength (1.5 T MRI system) [Toshiba Excelart Vantage, Japan] and a bilateral breast surface coil with the patient in the prone position.

* The study was performed in the second week of the menstrual cycle to minimize the amount of background parenchymal enhancement.

* Imaging acquisition protocol: 
A- Localizer

B- Non contrast-enhanced (pre-contrast) sequences/ series:

- Axial T1-weighted turbo spin echo $(\mathrm{TR} / \mathrm{TE}=500 /$ $5.3 \mathrm{~ms})$.

- Sagittal and Axial T2-weighted images using turbo spin echo $(\mathrm{TR} / \mathrm{TE}=120 / 4.9 \mathrm{~ms})$.

- Axial short time inversion recovery (STIR) (TR/TE $=80 / 6.5 \mathrm{~ms}$ ).

- A pre-contrast fat-saturated T2-weighted pulse sequence to separate cysts from solid masses.

C- Contrast-enhanced sequences/series:

- A bolus of contrast (gadolinium-diethylene tri amino penta-acetic acid; Gd-DTPA) (Magnavist, Schering AG Berlin, Germany) was injected manually intravenous at a dose of $0.1 \mathrm{mmol}$ per kilogram body weight $(0.1 \mathrm{mmol} / \mathrm{kg})$ followed by saline flush.

- Six dynamic acquisitions were taken: one before and five after intravenous injection of contrast material, using the volume interpolated GRE sequence (T1 High Resolution Isotropic Volumetric Examination) with the parameters $(\mathrm{TR} / \mathrm{TE}=2.8 / 9 \mathrm{~ms})$ and slice thickness $=1.5 \mathrm{~mm}$.

D- Post processing:

- Included subtraction, maximum intensity projection (MIP), and creating time/signal intensity curve by placing the region of interest (ROI) at the most enhanced part within the lesion

Interpretation of the imaging studies was performed via one of the participating radiologists, and in cases of interobserver disagreement, the case was discussed, and a joint consensus was reached. The findings were evaluated in accordance with the ACR BI-RADS 5th edition Lexicon (2013).

\section{Tissue sampling and analysis}

Percutaneous imaging-guided core biopsy or surgical excision was performed to acquire tumor sample. Specimens underwent immunohistochemistry to detect the levels of ER, PR, HER2 oncogene overexpression, and Ki-67. Stained slides were evaluated for nuclear ER or PR expression according to the College of American Pathologists guidelines ( $\geq 1 \%$ cutoff for positive) by pathologists. Ki-67 index $<14 \%$ was considered as low expression, and $\geq 14 \%$ was considered high expression.
HER2 expression on IHC was based on the cell membrane staining pattern with grade $2+$ considered equivocal, grade $3+$ considered positive, and grade $1+$ or 0 considered negative. All the equivocal samples were further analyzed with fluorescence in situ hybridization where FISH ratio higher than 2.2 or HER2 gene copy greater than 6.0 was considered positive.

Based on ER/PR/HER2 and Ki-67 expression status, breast cancers were categorized into four molecular subtypes in accordance with St. Gallen 2011 consensus surrogate definitions of the molecular subtypes:

- LA subtype

o ER- and/or PR-positive, HER2-negative, and Ki-67 $<14 \%$

- LB subtype: either

o ER- and/or PR-positive, HER2-negative, and $\mathrm{Ki}-67 \geq 14 \%$

O ER- and/or PR-positive and HER2-positive

- HER2-enriched type (HER2):

○ ER- and PR-negative and HER2-positive

- Triple-negative type (TN): $\circ$ ER, PR, and HER2-negative [12].

\section{Statistical analysis}

The data were collected, tabulated, and analyzed by SPSS version 17.0 (SPSS Inc., Chicago, IL, USA). Data was summarized using frequency and percentage for qualitative variables, mean, $\mathrm{SD}$, and range for quantitative variables. The imaging features were compared using univariate analyses of data. Comparison between the studied groups was done using Chi-square and Fisher's exact tests for qualitative variables, and Student's $t$ test or Mann Whitney $U$ test was used for comparing quantitative variables according to distribution of data. $P$ ( $P$ value) less than or equal to 0.05 was considered statistically significant.

\section{Results}

This study consisted of 60 patients with a mean age of $56.48 \pm 8.70$ (range $41-72$ years); 44 (73.3\%) were HRpositive, 13 (21.7\%) were HER2/neu-positive, 34 (56.7\%) were LA, 10 (16.7\%) were LB, 7 (11.7\%) were HER2/neuenriched, and 9 (15\%) were TNBC. Of the luminal B subgroup, 6 cases were HR+ve and HER2neu+ve, while 4 cases were $\mathrm{HR}+$ ve, HER2neu-ve, and Ki-67 $\geq 14 \%$. In one case, the lesion could not be detected on mammogram due to the extremely dense breast (Table 1 ).

Imaging features as regard hormonal receptor status (Fig. 1) On mammographic examination, HR-negative breast cancers were associated with circumscribed margins compared to HR-positive (35.7\% vs $8.1 \%$ ). There was no 
Table 1 Descriptive statistics of the studied group regarding age, histological type, HR, HER2neu receptor status, and molecular subtype

\begin{tabular}{|c|c|c|}
\hline & \multicolumn{2}{|c|}{$\begin{array}{l}\text { The studied groups } \\
N=60\end{array}$} \\
\hline \multicolumn{3}{|l|}{ Age } \\
\hline$X \pm S D$ & \multicolumn{2}{|c|}{$56.48 \pm 8.70$} \\
\hline \multirow[t]{2}{*}{ Range } & \multicolumn{2}{|c|}{$41-72$} \\
\hline & No. & $\%$ \\
\hline \multicolumn{3}{|l|}{ Histological type } \\
\hline IDC & 52 & 86.6 \\
\hline ILC & 6 & 10.0 \\
\hline Medullary & 2 & 3.3 \\
\hline \multicolumn{3}{|l|}{ HR } \\
\hline Positive & 44 & 73.3 \\
\hline Negative & 16 & 26.7 \\
\hline \multicolumn{3}{|l|}{ ER } \\
\hline Positive & 44 & 73.3 \\
\hline Negative & 16 & 26.7 \\
\hline \multicolumn{3}{|l|}{ PR } \\
\hline Positive & 34 & 56.6 \\
\hline Negative & 26 & 43.3 \\
\hline \multicolumn{3}{|l|}{ HER2/neu expression } \\
\hline Positive & 13 & 21.7 \\
\hline Negative & 47 & 78.3 \\
\hline \multicolumn{3}{|l|}{ Molecular type } \\
\hline Luminal A & 34 & 56.7 \\
\hline Luminal B & 10 & 16.7 \\
\hline HER2/neu-enriched & 7 & 11.7 \\
\hline Triple negative & 9 & 15.0 \\
\hline
\end{tabular}

NB: Of the Luminal B subgroup 6 cases were HR+ve and HER2neu+ve, while 4 cases were HR+ve, HER2neu-ve, and Ki-67 $\geq 14 \%$

$X$ mean, $S D$ standard deviation

statistically significant difference as regard the shape of the lesion and the presence of calcifications.

On ultrasound examination, HR-positive breast cancers were significantly associated with posterior acoustic shadowing (77.3\%) compared to $37.5 \%$ for HR-negative breast cancer cases $(P=0.004)$. Hormonal-negative breast cancers were more likely to be circumscribed compared to the hormonal-positive breast cancers (42.9\% vs $7.7 \%$, respectively) $(P=0.003)$. There was no statistical significance as regard the shape of the breast cancer or presence of ultrasonographic-detected calcifications between both groups.

The MRI findings in relation to the hormonal receptor status are summarized in Table 2. Round shape was noted more commonly in HR-negative breast cancers (23.1\%) compared to HR-positive breast cancers (2.8\%).
HR-negative breast cancers were more likely to present circumscribed margins compared to HR-positive breast cancers $(46.2 \%$ vs $8.3 \%$ respectively). They were also significantly associated with washout kinetics on DCE-MRI $(62.5 \%$ of hormonal-negative tumors vs $9.1 \%$ of hormonal-positive tumors). There was no statistical significance as regard the enhancement pattern.

\section{Imaging features as regard HER2/neu expression (Fig. 2)}

The mammographic features in relation to HER2/neu expression in breast cancer are summarized in Table 3. HER2/neu-positive breast cancers were more likely to present calcifications on mammography (69.2\%) compared to HER2/neu-negative tumors $(25.5 \%)(P=0.007)$.

On ultrasound examination, HER2/neu-positive breast cancers were significantly associated with calcifications on sonography (38.5\%) compared to HER2/neu-negative breast cancers $(8.5 \%)(P=0.02)$. There was no statistically significant difference as regards the shape of the lesion, margins, or posterior acoustic features.

The MRI findings in relation to the HER2/neu expression are summarized in Table 4. HER2/neu-negative breast cancers were more likely to present as mass lesions compared to HER2/neu-positive breast cancers ( $87.2 \%$ vs $61.5 \%$ respectively). There was no statistical significance as regard the enhancement pattern, shape, margin, or the enhancement kinetic curves.

Imaging features as regard the molecular subtype (Fig. 3) On mammography, breast cancers were more often irregular in shape in LB (100\%), HER2/neu (100\%), LA (70.4\%), and TNBC (44.4\%) with the TNBC presenting round shape in 2 cases $(22.2 \%)$ and oval shape in 3 cases (33.3\%). TNBC was associated with circumscribed margins $(55.6 \%)(P=0.003)$. HER2/neu-enriched breast cancers were more likely to present with calcifications which was seen in 5 cases $(71.4 \%)(P=0.08)$.

On ultrasound examination, there was no statistical significance as regard the shape of the breast cancer within different molecular subtypes. TNBC was more likely to have circumscribed margins $(66.7 \%)(P<0.001)$ with rounded or oval shape (66.7\%) and absent posterior acoustic shadowing $(88.9 \%)$ on sonographic examination.

The MRI findings of the four molecular subtypes of breast cancer are summarized in Table 5 . TNBC were more likely to present rim enhancement pattern (66.7\%), whereas heterogenous enhancement pattern was predominant in LA (70.6\%), LB (70\%), and HER2/neuenriched (85.7\%). TNBC was again shown to be more associated with round shape (33.3\%). HER2/neu-enriched and TNBC were significantly associated with washout kinetic curve pattern (57.1\% and $66.7 \%$ respectively). 


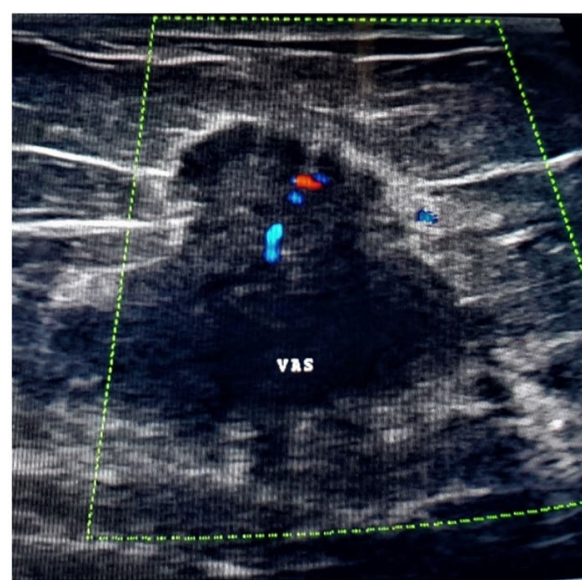

1.1
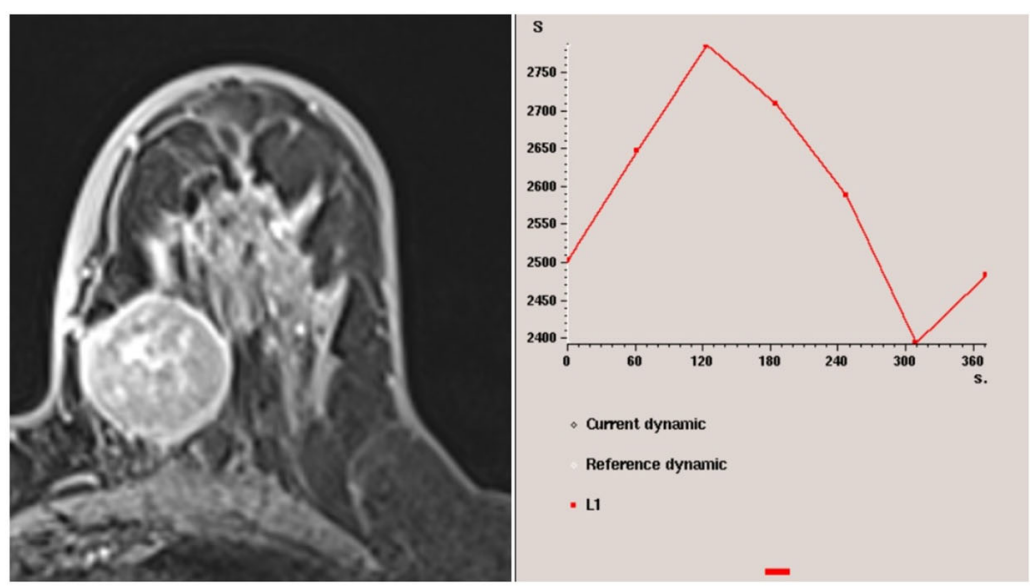

1.2

Fig. 1 Imaging features as regards the breast cancer hormonal receptor status. 1.1 An irregular non-circumscribed hypoechoic mass lesion with echogenic boundary, posterior acoustic shadowing, and weak intralesional vascularity with no detected calcification is noted. Pathologic analysis revealed HR positive, HER2/neu-negative, and luminal A subtype. 1.2 T1WI post contrast revealed a rounded circumscribed mass lesion with heterogenous enhancement. The lesion had malignant (washout) kinetics. Pathologic analysis revealed HR-negative, HER2/neu-negative, and TNBC subtype

\section{Discussion}

Breast cancer is a diverse group of diseases with different phenotypic and genotypic subtypes. This has significant therapeutic and prognostic effects with the molecular subtyping being an essential therapeutic requirement. Surrogate definitions of the intrinsic molecular subtypes depend upon hormonal receptor status, HER2neu overexpression, and Ki-67 index. This is usually done via immunohistochemistry (IHC) or fluorescence in situ hybridization (FISH) [12].

In our study, we correlated the hormonal receptor status, HER2neu expression status, and molecular subtype

Table 2 Relationship between hormonal receptors and MRI findings

\begin{tabular}{|c|c|c|c|c|c|c|}
\hline \multirow[t]{2}{*}{ MRI } & \multicolumn{2}{|c|}{$\begin{array}{l}\text { HR-positive } \\
N=44\end{array}$} & \multicolumn{2}{|c|}{$\begin{array}{l}\text { HR-negative } \\
N=16\end{array}$} & \multirow{2}{*}{$\begin{array}{l}\text { Test } \\
x^{2}\end{array}$} & \multirow[t]{2}{*}{$P$ value } \\
\hline & No & $\%$ & No & $\%$ & & \\
\hline Lesion & & & & & Fisher's & \\
\hline Mass & 36 & 81.8 & 13 & 81.2 & 0.003 & 1.0 \\
\hline NME & 8 & 18.2 & 3 & 18.8 & & \\
\hline \multicolumn{7}{|l|}{ Enhancement pattern } \\
\hline Homogenous enhancement & 7 & 15.9 & 1 & 6.2 & & \\
\hline Heterogenous enhancement & 31 & 70.5 & 9 & 56.2 & 4.52 & 0.10 \\
\hline RIM enhancement & 6 & 13.6 & 6 & 37.5 & & \\
\hline \multicolumn{7}{|l|}{ Shape of mass lesions } \\
\hline Round & 1 & 2.8 & 3 & 23.1 & 5.96 & 0.05 \\
\hline Oval & 6 & 16.7 & 3 & 23.1 & & \\
\hline Irregular & 29 & 80.6 & 7 & 58.2 & & \\
\hline Margin of mass lesions & & & & & Fisher's & \\
\hline Circumscribed & 3 & 8.3 & 6 & 46.2 & 9.11 & 0.007 \\
\hline Non circumscribed & 33 & 91.7 & 7 & 53.8 & & \\
\hline \multicolumn{7}{|l|}{ Kinetic } \\
\hline Plateau & 26 & 59.1 & 6 & 37.5 & & \\
\hline Washout & 4 & 9.1 & 10 & 62.5 & 20.46 & $<0.001$ \\
\hline Persistent & 14 & 31.8 & 0 & 0.0 & & \\
\hline
\end{tabular}




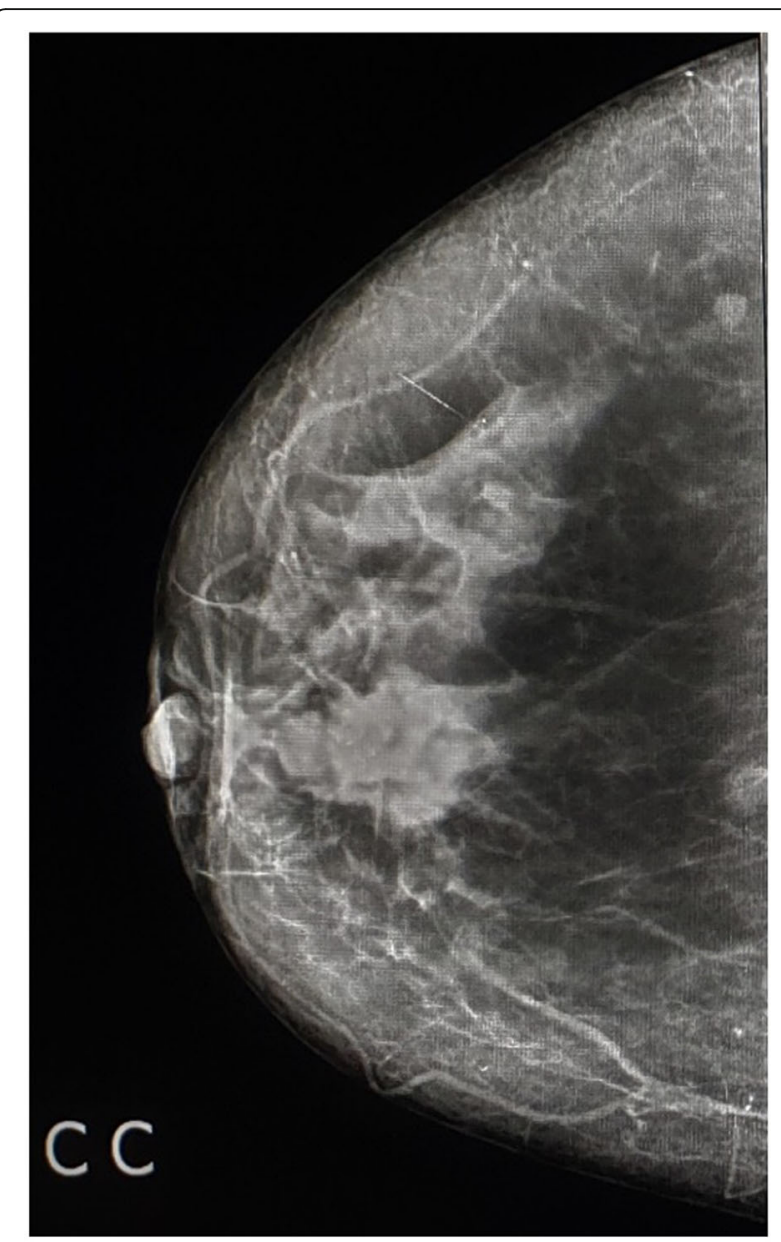

Fig. 2 Imaging features as regards the breast cancer HER2/neu receptor status. Multifocal irregular non-circumscribed (spiculated and indistinct) breast masses are noted. Pathologic analysis revealed HER2/neu-positive, HR-positive, and luminal B subtype

with imaging features as per mammosonography and MRI.

We found that hormonal-negative tumors were statistically different from hormonal-positive tumors as regards the mass margins, with the hormonal-negative tumors being more circumscribed on mammography, ultrasound, and MRI with a $P$ of $0.03,0.03$, and 0.007 respectively. This was similar to Shin et al. who reported that a circumscribed or microlobulated outline with posterior reinforcement was associated with a high grade and negativity of hormone receptors [13]. Like Song et al. [14], we found no statistically significant difference between hormonal-positive and negative groups as regards the calcification presence, morphology, and distribution. We also found that hormonal-positive tumors were associated with posterior acoustic shadowing in $72.7 \%$ of the patients $(P=0.004)$. This was in concordance to Rashmi et al., where they stated that luminal A and luminal B tumors (HR-positive tumors) had a significant association with non-circumscribed margins and acoustic shadowing $(P<0.0001)$ [15]. According to this study, we found that hormonal-negative tumors are more likely to show malignant DCE kinetics with washout curves (62.5\% of hormonal-negative tumors vs $9.1 \%$ of hormonal-positive tumors, $P$ value of $<0.001)$. Chen et al. reported similar findings, yet this was not statistically significant according to them $(P=0.15)$ [16]. No statistical significance was found on MRI between hormonal-positive and hormonal-negative tumors as regards the lesion appearance as mass or non-mass enhancement. This was different from Chen et al. results, where they reported that hormonal-negative tumors were more likely to present as non-mass enhancement compared to the hormonal-positive ones $(P<0.005)$ [16]. There was no significant correlation between internal enhancement patterns and the expression of hormonal receptors. This was in concordance with Tao et al. [17].

In this study, $70 \%$ of the HER $2 /$ neu-positive tumors had calcifications with only $25.5 \%$ of the HER $2 /$ neunegative tumors presenting calcifications $(P=0.007)$. This goes in concordance with Sun et al. who reported malignant calcification to be more frequent in HER2/ neu-positive tumors $(P=0.001)$ and Boisserie-Lacroix et al. who stated that the presence of calcifications in the mammogram may predict a HER2/neu-positive status when the HER 2 score is equivocally $2+$ in immunohistochemistry [18, 19].

Elias and colleagues reported that when considering only mass lesions, multifocality was related to increased HER2 overexpression $(P<0.001)$ [1]. This was similar to what we reported on mammographic examination, where HER2/neu-negative was more likely to be unifocal than HER/2neu-positive tumors (92.5\% vs $36.4 \%$ respectively) $(P<0.001)$. No statistical difference between HER2-positive and HER2-negative as regards the DCE kinetics was noted in this study. This was opposite to Elias et al., where an increased chance of HER2 overexpression was noted with washout or fast initial kinetics on DCE-MRI ( $P=0.01$ and $P<0.01$ respectively) [1].

Ko et al. found a significant difference between TNBC and non-TNBC as regard the microcalcifications and the focal asymmetries. They reported that TNBC less frequently had associated microcalcifications $(P=0.0055)$, while focal asymmetries were more frequent in the TNBC (22\%, $P=0.003)$ [20]. We reported similar findings as regards the less common incidence of microcalcifications in TNBC but not up to a statistically significant level $(P=0.08)$, yet we did not report any case of asymmetry in the TNBC cases. This difference may be due to the smaller number of cases in our study.

In this study, luminal $A$, luminal B, and HER2enriched groups were associated with non-circumscribed 
Table 3 Relationship between HER2/neu status and mammography findings

\begin{tabular}{|c|c|c|c|c|c|c|}
\hline \multirow{2}{*}{$\begin{array}{l}\text { Mammography } \\
\text { Size }\end{array}$} & \multicolumn{2}{|c|}{$\begin{array}{l}\text { HER2/neu-positive } \\
N=13\end{array}$} & \multicolumn{2}{|c|}{$\begin{array}{l}\text { HER2/neu-negative } \\
N=46\end{array}$} & \multirow{2}{*}{$\begin{array}{l}\text { Test } \\
\mathbf{U}\end{array}$} & \multirow[t]{2}{*}{$P$ value } \\
\hline & & & & & & \\
\hline$X \pm S D$ & 2.14 & & 2.55 & & 1.06 & 0.29 \\
\hline \multirow[t]{2}{*}{ Range } & $1.2-$ & & $1.2-$ & & & \\
\hline & No & $\%$ & No & $\%$ & $x^{2}$ & \\
\hline \multicolumn{7}{|l|}{ Lesion } \\
\hline Mass & 11 & 84.8 & 40 & 87.0 & & \\
\hline Architectural changes & 1 & 7.7 & 3 & 6.5 & 0.05 & 0.98 \\
\hline Asymmetry & 1 & 7.7 & 3 & 6.5 & & \\
\hline Focality of mass lesions & & & & & Fisher's & \\
\hline Unifocal & 4 & 36.4 & 37 & 92.5 & & $<0.001$ \\
\hline Multifocal & 7 & 63.6 & 3 & 7.5 & 17.25 & \\
\hline \multicolumn{7}{|l|}{ Shape of mass lesions } \\
\hline Round & 0 & 0.0 & 4 & 10.0 & 4.80 & 0.09 \\
\hline Oval & 0 & 0.0 & 9 & 22.5 & & \\
\hline Irregular & 11 & 100 & 27 & 67.5 & & \\
\hline Calcification & & & & & Fisher's & \\
\hline Present & 9 & 69.2 & 12 & 25.5 & & 0.007 \\
\hline Absent & 4 & 30.8 & 34 & 74.5 & 8.55 & \\
\hline
\end{tabular}

$\mathrm{X}^{2}=$ Chi squared test

Table 4 Relationship between HER2/neu receptor status and MRI findings

\begin{tabular}{|c|c|c|c|c|c|c|}
\hline \multirow[t]{2}{*}{$\mathrm{MRI}$} & \multicolumn{2}{|c|}{$\begin{array}{l}\text { HER2/neu-positive } \\
N=13\end{array}$} & \multicolumn{2}{|c|}{$\begin{array}{l}\text { HER2/neu negative } \\
N=47\end{array}$} & \multirow{2}{*}{$\begin{array}{l}\text { Test } \\
x^{\mathbf{2}}\end{array}$} & \multirow[t]{2}{*}{$P$ value } \\
\hline & $\overline{\mathrm{No}}$ & $\%$ & $\overline{\mathrm{No}}$ & $\%$ & & \\
\hline Lesion & & & & & Fisher's & \\
\hline Mass & 8 & 61.5 & 41 & 87.2 & 4.94 & 0.049 \\
\hline NME & 5 & 38.5 & 6 & 12.8 & & \\
\hline \multicolumn{7}{|l|}{ Enhancement pattern } \\
\hline Homogenous enhancement & 1 & 7.7 & 7 & 14.9 & & \\
\hline Heterogenous enhancement & 11 & 84.6 & 29 & 61.7 & 2.45 & 0.29 \\
\hline Rim enhancement & 1 & 7.7 & 11 & 23.4 & & \\
\hline \multicolumn{7}{|l|}{ Shape of mass lesions } \\
\hline Round & 0 & 0.0 & 4 & 9.8 & 3.45 & 0.18 \\
\hline Oval & 0 & 0.0 & 9 & 22.0 & & \\
\hline Irregular & 8 & 100 & 28 & 68.3 & & \\
\hline Margin of mass lesions & & & & & Fisher's & \\
\hline Circumscribed & 0 & 0.0 & 9 & 22.0 & 2.15 & 0.32 \\
\hline Non-circumscribed & 8 & 100 & 32 & 78.0 & & \\
\hline \multicolumn{7}{|l|}{ Kinetic } \\
\hline Plateau & 7 & 53.8 & 25 & 53.2 & 0.84 & 0.66 \\
\hline Washout & 4 & 30.8 & 10 & 21.3 & & \\
\hline Persistent & 2 & 15.4 & 12 & 25.55 & & \\
\hline
\end{tabular}




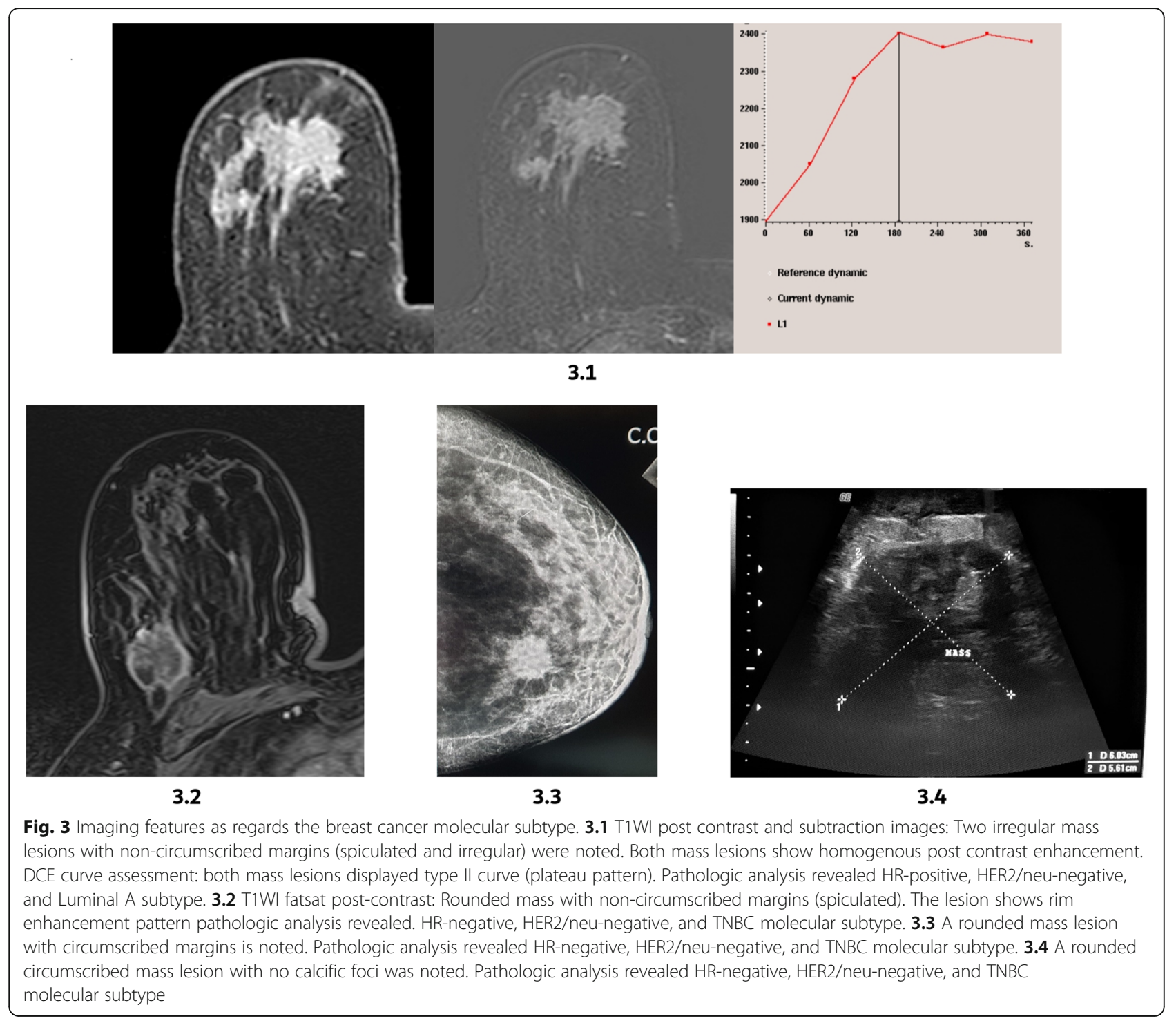

margins with luminal A and B tumors presenting posterior acoustic shadowing. This was in concordance to Zhang et al. [21].

In this study, all of the TNBC lesions were masses as seen per mammosonography and MRI. This was different from Dogan et al., as they reported mass lesions in $77.3 \%$ of the cases and non-mass enhancement in $22.7 \%$ of the cases on MRI and mass lesion in $86 \%$ of the cases on US [22]. We also reported that TNBC mass lesions on sonography and MRI were associated with circumscribed margins in $66.7 \%$ of the cases. This was different from Dogan et al., where they reported that mass lesions on US had circumscribed margins in $21.1 \%$ of the masses [22]. Our findings are similar to Ko et al., where they reported on ultrasound examination that $86 \%$ of the TNBC presented as masses and significantly had circumscribed (57\%) as opposed to non-circumscribed margins [20].
We also reported a significant difference between TNBC and other molecular subtypes regarding the internal enhancement pattern of mass lesions; rim internal enhancement was predominant in TNBC mass lesions in this study compared to the predominant heterogenous enhancement pattern in the other subtypes. This may be attributed to increased tumoral necrosis in TN breast cancers. Our results were consistent with Azzam et al. and Youk et al., where they reported similar results $(P=$ 0.001 and $P<0.0001$, respectively) [23, 24]. Teifke et al. noted that rim enhancement is usually associated with high-grade tumors and is considered the most useful MR imaging feature for identifying TN cancers [25].

The major limitation of this study was a relatively small number of patients. Another limitation is the interobserver variability in reporting the different lesions which is likely to cause some variability in the results 
Table 5 Relationship between molecular subtypes and MRI findings

\begin{tabular}{|c|c|c|c|c|c|c|c|c|c|c|}
\hline \multirow[t]{2}{*}{$\overline{M R I}$} & \multicolumn{2}{|c|}{$\begin{array}{l}\text { Luminal A } \\
N=34\end{array}$} & \multicolumn{2}{|c|}{$\begin{array}{l}\text { Luminal B } \\
N=10\end{array}$} & \multicolumn{2}{|c|}{$\begin{array}{l}\text { HER2/neu-enriched } \\
N=7\end{array}$} & \multicolumn{2}{|c|}{$\begin{array}{l}\text { Triple negative } \\
N=9\end{array}$} & \multirow{2}{*}{$\begin{array}{l}\text { Test } \\
X^{2}\end{array}$} & \multirow[t]{2}{*}{$P$ value } \\
\hline & No & $\%$ & No & $\%$ & No & $\%$ & No & $\%$ & & \\
\hline \multicolumn{11}{|l|}{ Lesion } \\
\hline Mass & 28 & 82.4 & 8 & 80 & 4 & 57.1 & 9 & 100 & 4.86 & 0.18 \\
\hline NME & 6 & 17.6 & 2 & 20 & 3 & 42.9 & 0 & 0.0 & & \\
\hline \multicolumn{11}{|l|}{ Enhancement pattern } \\
\hline Homogenous enhancement & 5 & 14.7 & 2 & 20.0 & 1 & 14.3 & 0 & 0.0 & & \\
\hline Heterogenous enhancement & 24 & 70.6 & 7 & 70.0 & 6 & 85.7 & 3 & 33.3 & 15.74 & 0.02 \\
\hline Rim enhancement & 5 & 14.7 & 1 & 10.0 & 0 & 0.0 & 6 & 66.7 & & \\
\hline \multicolumn{11}{|l|}{ Shape of mass lesions } \\
\hline Round & 1 & 3.6 & 0 & 0.0 & 0 & 0.0 & 3 & 33.3 & 13.34 & 0.03 \\
\hline Oval & 5 & 17.9 & 1 & 12.5 & 0 & 0.0 & 3 & 33.3 & & \\
\hline Irregular & 22 & 78.6 & 7 & 87.5 & 4 & 100 & 3 & 33.3 & & \\
\hline \multicolumn{11}{|l|}{ Margin of mass lesions } \\
\hline Circumscribed & 2 & 7.1 & 1 & 12.5 & 0 & 0 & 6 & 66.7 & 17.44 & 0.001 \\
\hline Non circumscribed & 26 & 92.9 & 7 & 87.5 & 4 & 100 & 3 & 33.3 & & \\
\hline \multicolumn{11}{|l|}{ Kinetic } \\
\hline Plateau & 20 & 58.8 & 6 & 60.0 & 3 & 42.9 & 3 & 33.3 & & \\
\hline Washout & 3 & 8.8 & 1 & 10.0 & 4 & 57.1 & 6 & 66.7 & 20.7 & 0.002 \\
\hline Persistent & 11 & 32.4 & 3 & 30.0 & 0 & 0.0 & 0 & 0.0 & & \\
\hline
\end{tabular}

reported by different investigators. It is worth noting that possibility of intratumoral heterogeneity especially in the case where the histopathological assessment was via core biopsy may contribute to discordance in ER, PR, and HER2 status, with possible implications for breast cancer subtype classification.

\section{Conclusion}

This study showed that tumor's margins, microcalcifications on mammography, posterior acoustic features on ultrasonography, enhancement pattern, and kinetics on MRI strongly correlate with hormonal receptor status, HER2neu expression, and molecular subtype. Hormonalpositive tumors tend to be of non-circumscribed margins with posterior acoustic shadowing on ultrasonography. HR-negative tumors tend to be larger, more commonly associated with circumscribed margins and present with washout kinetics on MRI. HER2neu-positive tumors tend to present microcalcifications. TNBC is usually circumscribed masses with washout kinetics on MRI.

\section{Abbreviations}

HR: Hormonal receptor; US: Ultrasonography; MRI: Magnetic resonance imaging; FISH: Fluorescence in situ hybridization; DCE: Dynamic contrast enhancement; TNBC: Triple-negative breast cancer;

IHC: Immunohistochemistry; ER: Estrogen receptor; PR: Progesterone receptor; CC: Craniocaudal; MLO: Medial lateral oblique; GRE: Gradientrecalled echo; MIP: Maximum intensity projection; ROI: Region of interest

\section{Acknowledgements}

There is no acknowledgement.

Availability for data and materials

Data will be available upon request via contacting the corresponding author.

Authors' contributions

MA, AE, AA, and WM contributed equally to study design, data collection, analysis, and interpretation of results. All authors read and approved the final manuscript

\section{Funding}

There is no funding.

Ethics approval and consent to participate

All study procedures were conducted in accordance with the declaration of Helsinki and were approved by the ethical committee under the supervision of Prof. Dr. Walaa Farid and the Menoufia Faculty of Medicine Council, reference number 3/86/1/9/2016. All data were extracted after taking fully informed written consent from each patient involved in the study after explanation of the procedures and the importance of the study, and the confidentiality of the patient's data was guaranteed.

\section{Consent for publication}

All patients included in this research gave written informed consent to publish the data contained within this study.

\section{Competing interests}

The authors declare that they have no competing interests.

\section{Author details}

'Department of Radiodiagnosis, Faculty of Medicine, Menoufia University, Shibin El Kom, Menoufia 32511, Egypt. ${ }^{2}$ Department of Clinical Oncology and Nuclear Medicine, Faculty of Medicine, Menoufia University, Shibin El Kom, Menoufia 32511, Egypt. 
Received: 5 March 2020 Accepted: 27 May 2020

Published online: 09 June 2020

\section{References}

1. Elias SG, Adams A, Wisner DJ, Esserman LJ, van't Veer LJ, Mali WPTM, Gilhuijs KGA, Hylton NM (2014) Imaging features of HER2 overexpression in breast cancer: a systematic review and meta-analysis. Cancer Epidemiol Biomarkers Prev 23:1464-1483. https://doi.org/10.1158/1055-9965.EPI-13-1170

2. Trop I, LeBlanc SM, David J, Lalonde L, Tran-Thanh D, Labelle M, El Khoury MM (2014) Molecular classification of infiltrating breast cancer: toward personalized therapy. RadioGraphics 34:1178-1195. https://doi.org/10.1148/ rg.345130049

3. Cho N (2016) Molecular subtypes and imaging phenotypes of breast cancer. Ultrasonography 35:281-288. https://doi.org/10.14366/usg.16030

4. Parker JS, Mullins $M$, Cheang MCU, Leung S, Voduc D, Vickery T, Davies S, Fauron C, He X, Hu Z, Quackenbush JF, Stijleman IJ, Palazzo J, Marron JS, Nobel AB, Mardis E, Nielsen TO, Ellis MJ, Perou CM, Bernard PS (2009) Supervised risk predictor of breast cancer based on intrinsic subtypes. J Clin Oncol 27:1160-1167. https://doi.org/10.1200/JCO.2008.18.1370

5. Goldhirsch A, Winer EP, Coates AS, Gelber RD, Piccart-Gebhart M, Thürlimann B, Senn H-J, Albain KS, André F, Bergh J, Bonnefoi H, BretelMorales D, Burstein H, Cardoso F, Castiglione-Gertsch M, Coates AS, Colleoni M, Costa A, Curigliano G, Davidson NE, Di Leo A, Ejlertsen B, Forbes JF, Gelber RD, Gnant M, Goldhirsch A, Goodwin P, Goss PE, Harris JR, Hayes DF, Hudis CA, Ingle JN, Jassem J, Jiang Z, Karlsson P, Loibl S, Morrow M, Namer M, Kent Osborne C, Partridge AH, Penault-Llorca F, Perou CM, PiccartGebhart MJ, Pritchard KI, Rutgers EJT, Sedlmayer F, Semiglazov V, Shao Z-M, Smith I, Thürlimann B, Toi M, Tutt A, Untch M, Viale G, Watanabe T, Wilcken N, Winer EP, Wood WC (2013) Personalizing the treatment of women with early breast cancer: highlights of the St Gallen International Expert Consensus on the Primary Therapy of Early Breast Cancer 2013. Ann Oncol 24:2206-2223. https://doi.org/10.1093/annonc/mdt303

6. Rakha EA, Chan S (2011) Metastatic triple-negative breast cancer. Clin Oncol (R Coll Radiol) 23:587-600. https://doi.org/10.1016/j.clon.2011.03.013

7. Meisel JL, Venur VA, Gnant M, Carey L (2018) Evolution of targeted therapy in breast cancer: where precision medicine began. American Society of Clinical Oncology Educational Book 78-86 . https://doi.org/10.1200/EDBK_ 201037

8. Geyer FC, Pareja F, Weigelt B, Rakha E, Ellis IO, Schnitt SJ, Reis-Filho JS (2017) The spectrum of triple-negative breast disease. Am J Pathol 187:2139-2151. https://doi.org/10.1016/i.ajpath.2017.03.016

9. Network TCGA (2012) Comprehensive molecular portraits of human breast tumors. Nature 490:61. https://doi.org/10.1038/nature11412

10. Russnes HG, Lingjærde OC, Børresen-Dale A-L, Caldas C (2017) Breast cancer molecular stratification: from intrinsic subtypes to integrative clusters. The American Journal of Pathology 187:2152-2162. https://doi.org/10.1016/j. ajpath.2017.04.022

11. Bansal C, Sharma A, Pujani M, Pujani M, Sharma KL, Srivastava AN, Singh US (2017) Correlation of hormone receptor and human epidermal growth factor receptor-2/neu expression in breast cancer with various clinicopathologic factors. Indian Journal of Medical and Paediatric Oncology : Official Journal of Indian Society of Medical \& Paediatric Oncology 38:483. https://doi.org/10.4103/ijmpo.ijmpo_98_16

12. Goldhirsch A, Wood WC, Coates AS, Gelber RD, Thürlimann B, Senn H-J (2011) Strategies for subtypes - dealing with the diversity of breast cancer: highlights of the St Gallen International Expert Consensus on the Primary Therapy of Early Breast Cancer 2011. Ann Oncol 22:1736-1747. https://doi. org/10.1093/annonc/mdr304

13. Shin HJ, Kim HH, Huh MO, Kim MJ, Yi A, Kim H, Son BH, Ahn SH (2011) Correlation between mammographic and sonographic findings and prognostic factors in patients with node-negative invasive breast cancer. BJR 84:19-30. https://doi.org/10.1259/bjr/92960562

14. Song SE, Bae MS, Chang JM, Cho N, Ryu HS, Moon WK (2017) MR and mammographic imaging features of HER2-positive breast cancers according to hormone receptor status: a retrospective comparative study. Acta Radiol 58:792-799. https://doi.org/10.1177/0284185116673119

15. Rashmi S, Kamala S, Murthy SS, Kotha S, Rao YS, Chaudhary KV (2018) Predicting the molecular subtype of breast cancer based on mammography and ultrasound findings. Indian Journal of Radiology and Imaging 28:354. https://doi.org/10.4103/ijri.|JRI_78_18
16. Chen J-H, Baik H-M, Nalcioglu O, Su M-Y (2008) Estrogen receptor and breast MR imaging features: a correlation study. J Magn Reson Imaging 27: 825-833. https://doi.org/10.1002/jmri.21330

17. Tao W, Hu C, Bai G, Zhu Y, Zhu Y (2018) Correlation between the dynamic contrast-enhanced MRI features and prognostic factors in breast cancer. Medicine (Baltimore):97. https://doi.org/10.1097/MD.0000000000011530

18. Boisserie-Lacroix M, Hurtevent-Labrot G, Ferron S, Lippa N, Bonnefoi H, Mac Grogan G (2013) Correlation between imaging and molecular classification of breast cancers. Diagnostic and Interventional Imaging 94:1069-1080. https://doi.org/10.1016/j.diii.2013.04.010

19. Sun S-S, Zhang B, Zhao H-M, Cao X-C (2014) Association between mammographic features and clinicopathological characteristics in invasive ductal carcinoma of breast cancer. Molecular and Clinical Oncology 2:623629. https://doi.org/10.3892/mco.2014.297

20. Ko ES, Lee BH, Kim H-A, Noh W-C, Kim MS, Lee S-A (2010) Triple-negative breast cancer: correlation between imaging and pathological findings. Eur Radiol 20:1111-1117. https://doi.org/10.1007/s00330-009-1656-3

21. Zhang L, Li J, Xiao Y, Cui H, Du G, Wang Y, Li Z, Wu T, Li X, Tian J (2015) Identifying ultrasound and clinical features of breast cancer molecular subtypes by ensemble decision. Sci Rep 5. https://doi.org/10.1038/ srep11085

22. Dogan BE, Gonzalez-Angulo AM, Gilcrease M, Dryden MJ, Yang WT (2010) Multimodality imaging of triple receptor-negative tumors with mammography, ultrasound, and MRI. AJR Am J Roentgenol 194:1160-1166. https://doi.org/10.2214/AJR.09.2355

23. Azzam H, Kamal R, El-Assaly H, Metwally LIA (2019) The value of dynamic contrast-enhanced MRI in differentiating triple-negative breast cancer from other subtypes. Egyptian Journal of Radiology and Nuclear Medicine 50:106. https://doi.org/10.1186/s43055-019-0118-4

24. Youk JH, Son EJ, Chung J, Kim J-A, Kim E-K (2012) Triple-negative invasive breast cancer on dynamic contrast-enhanced and diffusion-weighted MR imaging: comparison with other breast cancer subtypes. Eur Radiol 22: 1724-1734. https://doi.org/10.1007/s00330-012-2425-2

25. Teifke A, Behr O, Schmidt M, Victor A, Vomweg TW, Thelen M, Lehr H-A (2006) Dynamic MR imaging of breast lesions: correlation with microvesse distribution pattern and histologic characteristics of prognosis. Radiology 239:351-360. https://doi.org/10.1148/radiol.2392050205

\section{Publisher's Note}

Springer Nature remains neutral with regard to jurisdictional claims in published maps and institutional affiliations.

\section{Submit your manuscript to a SpringerOpen ${ }^{\circ}$ journal and benefit from:}

- Convenient online submission

- Rigorous peer review

- Open access: articles freely available online

- High visibility within the field

- Retaining the copyright to your article

Submit your next manuscript at $>$ springeropen.com 